\title{
EFFECT OF NEPTAZANE ON INTRA-OCULAR PRESSURE IN RELATION TO ITS SYSTEMIC ACTION AND ITS CLINICAL APPLICATION*†
}

\author{
BY \\ DOROTHY A. CAMPBELL \\ Research Department, Birmingham and Midland Eye Hospita.
}

Ophthalmologists are already familiar with the clinical use of Diamox for the reduction of intra-ocular pressure in both acute and chronic cases of glaucoma. It is therefore of considerable interest to find a second compound, Neptazane, of close chemical relationship to Diamox which is a possible alternative or substitute particularly for cases which fail to respond to Diamox or which develop unpleasant side-effects.

Neptazane is already being used therapeutically in America and its clinical effects have been reported by Becker (1957). Its immediate effect on intra-ocular pressure is said to be slower and less dramatic than that of Diamox and in short-term therapy it was found to be effective in a smaller percentage of patients (68 as compared with 83 per cent.). It appears to be particularly suitable and equally as effective as Diamox for long-term therapy. It provokes very few unpleasant side-effects, paraesthesia, drowsiness, and gastro-intestinal disturbances being much less common than after Diamox. No instances of ureteral colic have been recorded in spite of the fact that it is excreted slowly. It is effective in smaller doses, $125 \mathrm{mg}$. Neptazane being regarded as equivalent to $250 \mathrm{mg}$. Diamox, although this alone offers no particular reason for its preferential use. The optimum dose has been cited as $100 \mathrm{mg}$., two or three times daily, very little benefit being obtained with larger or smaller doses.

The pharmacological action of Neptazane has been well demonstrated by Sisson and Maren (1956) and Maren (1956) (see also unpublished Lederle reports, 1958). Like Diamox it is a carbonic anhydrase inhibitor with an in vitro action 1.6 times that of Diamox. It penetrates well into the aqueous humour and promotes an immediate diuresis and excretion of electrolytes. In the dog, during the first $6 \mathrm{hrs}$, there is an increased loss of sodium, potassium, and bicarbonate and a rise in the urinary $\mathrm{pH}$ which ceases in $18 \mathrm{hrs}$ after a single dose of $5 \mathrm{mg} . / \mathrm{kg}$.

* Received for publication September 9, 1959.

+ This paper was delivered at the Joint Meeting of the Irish Ophthalmological Society and the Section of Ophthalmology at the Royal Society of Medicine at Belfast, in May, 1959. 
In man Neptazane reaches its maximum concentration in the blood within 3 to $6 \mathrm{hrs}$ after a dose of 5 to $7.5 \mathrm{mg}$. $/ \mathrm{kg}$. Renal clearance is 4 to 8 times slower than that of Diamox and 24-hr recoveries from urine were only 15-19 per cent. of the dose. It has been estimated that $43-58$ per cent. of a small dose is metabolized.

In man the 24-hr urinary loss of sodium and potassium is said to be greater than after a comparable single dose of Diamox (Lederle). The urinary citrate excretion is, however, not depressed.

It is still an interesting matter for discussion and one of great physiological interest whether these carbonic anhydrase inhibitors such as Diamox or Neptazane lower the intra-ocular pressure by diminishing the formation of aqueous humour (Becker and Constant, 1955; Langham and Lee, 1957; Langham, 1958) as the result of suppressing the formation of bicarbonate ions (Becker, 1956), or whether their effect on the eye is secondary to the osmotic changes in the blood induced by diuresis and by the loss of cations particularly of sodium.

Langham (1958) has recently compared the specificity and comparative activity of the two compounds with regard to their action on intra-ocular pressure.

In rabbits and cats, Neptazane was two to three times more active than Diamox in lowering the intra-ocular pressure, and it also caused an immediate and concurrent decrease in the rate of formation of aqueous humour.

Neptazane was also effective in man, and Langham found that single doses of 250 and $125 \mathrm{mg}$. depressed the intra-ocular pressure for a minimum of $20 \mathrm{hrs}$ and $12 \mathrm{hrs}$ respectively. His records in human subjects were, however, obscured by the concurrent use of miotics.

By comparison with allied chemical compounds, Langham also demonstrated that the specificity of the action of Neptazane and of Diamox upon the eye depended on the presence of a free sulphonamide group-which is essential also for carbonic anhydrase inhibition.

Having full regard to the observations which have already been carried out upon the action of Neptazane, it appeared highly desirable to explore the relationship between its intra-ocular and systemic effects, since this proved to be of considerable significance in the case of Diamox and led to its wiser therapeutic use.

As in the case of Diamox (Campbell, Tonks, and Jones, 1956; Campbell, Jones, Renner, and Tonks, 1957; Campbell, Renner, and Tonks, 1958), the effect of single and repeated doses of Neptazane was investigated in glaucomatous patients without the concurrent use of miotics.

As far as its systemic effects were concerned we had in mind two particular problems:

(a) Whether it induces a state of acidosis, and how long this persists; 
(b) The possible danger that the body may be drained of electrolytes by continuous use of the drug.

The opportunity was taken to compare the action of Neptazane with that of Diamox under the same experimental conditions.

\section{Experimental Procedure}

In order to get a clear assessment of the effect of any drug which lowers intraocular pressure, we have found by experience that the subject should be at rest in bed, or sitting quietly in a chair, and that no miotics should be used. The diurnal variation in pressure should be recorded for a preliminary period of 2 to 3 days, since individual subjects often show a considerable rise and fall which tends to lessen with rest. Tonometric readings taken at random as an out-patient are of little value-since the peak of the intra-ocular pressure is often never found. Therapeutically it is important to know in each individual the time of day at which this peak occurs, so that the drug can be administered at the optimum time, i.e. just before the peak.

It is desirable to take additional precautions during such investigations, such as keeping the patient on a known diet, low in sodium, and in a state of steady hydration throughout the day, knowing for instance that the imbibition of a large amount of fluid can affect the intra-ocular pressure.

Such precautions were observed in these investigations and the same routine was adopted as already described in our previous work on Diamox.

Five volunteer subjects affected with glaucoma were tested each for a period of from 5 to 10 days under strictly comparable conditions. In each of these patients the angles of the anterior chamber were "open" or of medium size.

\section{Results}

\section{Effects of a Single Dose of Neptazane}

(a) Ocular Response.-It was soon evident from preliminary tests that, although a dose of $125 \mathrm{mg}$. Neptazane can depress the intra-ocular pressure for as long as $18 \mathrm{hrs}$, a single dose of $250 \mathrm{mg}$. is much more effective in the glaucomatous eye.

The response varied in different individuals (see Fig. 1, overleaf, in which each curve is the average response for 2 eyes in each individual). A dose of $250 \mathrm{mg}$. Neptazane caused an immediate average fall of $15 \mathrm{~mm} . \mathrm{Hg}$ during the first $4 \mathrm{hrs}$, and the effect lasted for as long as $\mathbf{4 3} \mathrm{hrs}$. There was an interim peak in each case at about $19 \mathrm{hrs}-$ following the pattern of the normal diurnal excursion. 


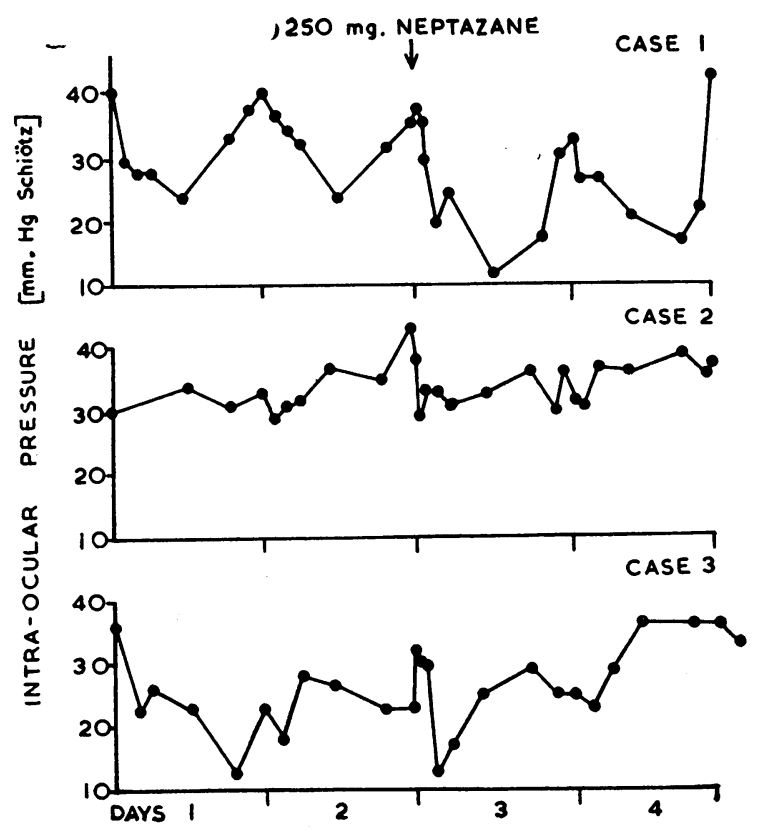

FIG. 1.-Effect of a single dose of $250 \mathrm{mg}$. Neptazane on intra-ocular pressure. The intra-ocular pressure recorded is the average of two eyes in each individual.

(b) Systemic Response.-The effect on the electrolytes of the blood is shown in the Table (below).

Sodium and chloride showed an immediate and noticeable fall and remained at a low level for $48 \mathrm{hrs}$ and $24 \mathrm{hrs}$ respectively. Sulphates were similarly affected for $48 \mathrm{hrs}$. The bicarbonate was unaffected for the first $6 \mathrm{hrs}$, i.e. during the period of rapid fall of intra-ocular pressure, but then declined for more than $48 \mathrm{hrs}$. Potassium, magnesium, and proteins fell during the first $6 \mathrm{hrs}$. Calcium was relatively unaffected and the phosphates rose temporarily.

CHANGES IN ELECTROLYTES OF THE BLOOD AFTER A SINGLE DOSE OF NEPTAZANE $(250 \mathrm{mg}$.)*

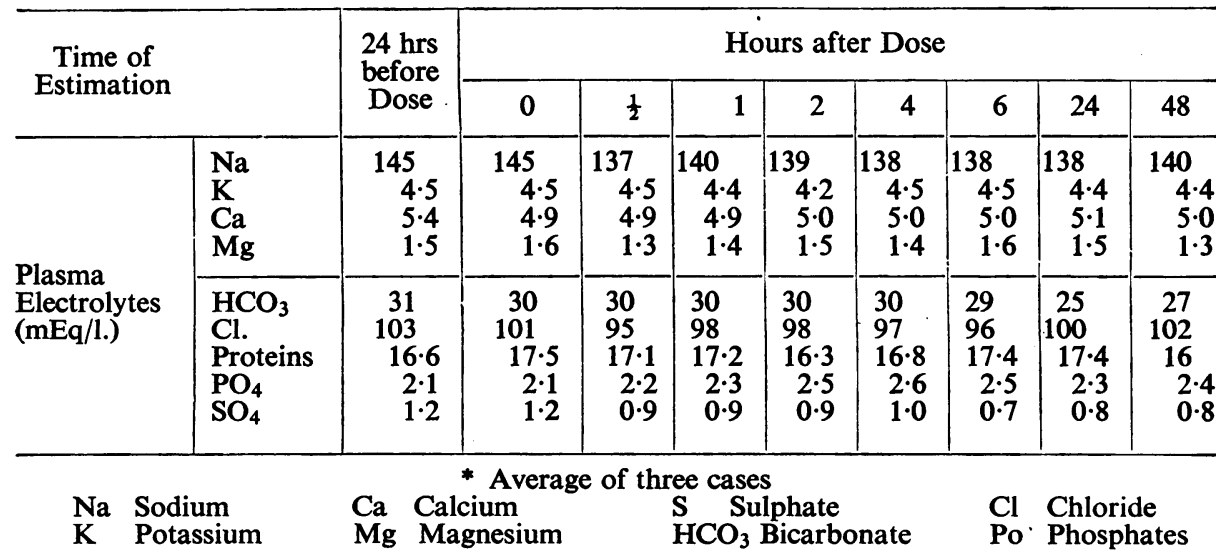


Urinary excretion showed an immediate diuresis and a rise in output of sodium and of potassium which coincided with the period of fall in intraocular pressure (Fig. 2). The urine was markedly alkaline with a $\mathrm{pH}$ above 7.0.
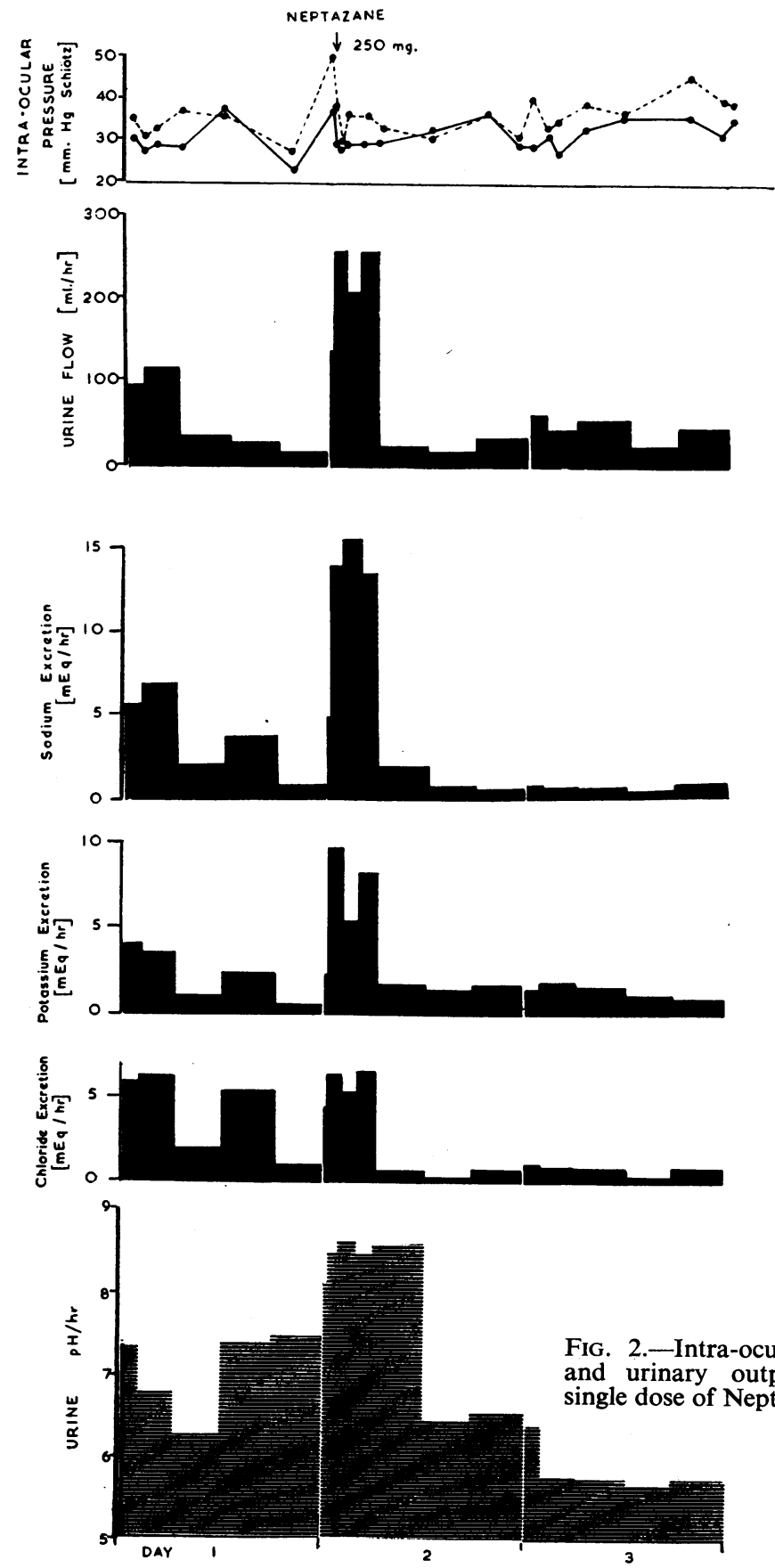
In comparing the 24-hr output after Neptazane with that of the previous day, there was a real increase in volume, and in sodium and potassium excretion, but the chloride output was unchanged or showed a slight decline.

In the period of 24 to $48 \mathrm{hrs}$ after Neptazane the urine was acid and its volume returned to its predosage level. The output of sodium, potassium, and chloride fell to below the predosage level.

(c) Comparison with Effect of Diamox.-The effect of $250 \mathrm{mg}$. Neptazane, compared with that of $250 \mathrm{mg}$. Diamox, may be summarized as follows:

(i) The intra-ocular pressure fell more slowly during the first $3 \mathrm{hrs}$, but reached the same level after 4 hrs as that caused by Diamox (Fig. 3); it remained below its initial value for over $24 \mathrm{hrs}$ after either drug.

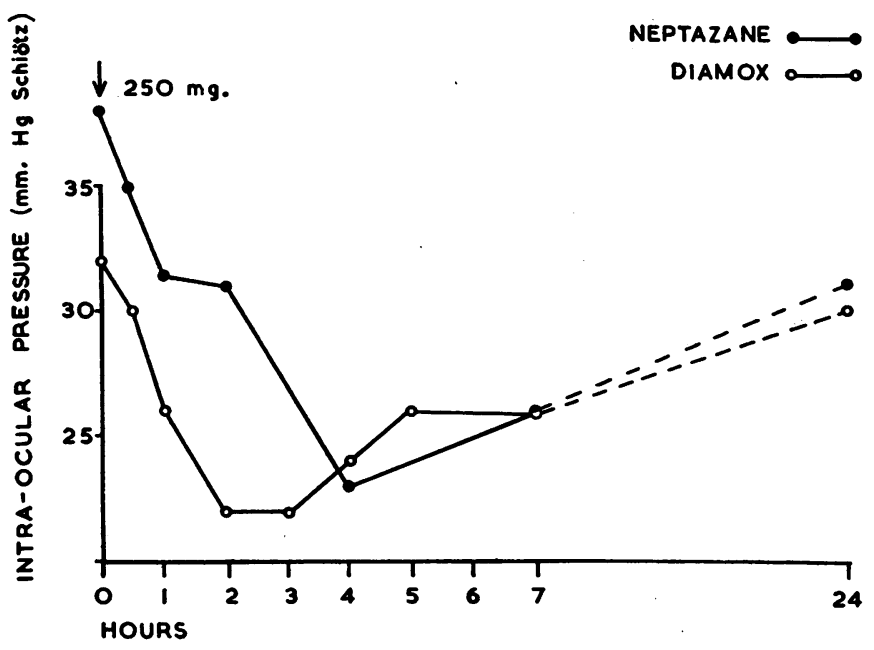

Fig. 3.-Average effect on intra-ocular pressure of a single dose of Neptazane compared with a single dose of Diamox.

(ii) In the blood the changes in sodium, potassium, proteins, and bicarbonate followed much the same pattern, the fall in the bicarbonate being longer delayed after Neptazane than after Diamox. There was a difference in the behaviour of the chlorides in the first $6 \mathrm{hrs}$; they tended to rise after Diamox and to fall after Neptazane (Fig. 4, opposite). 

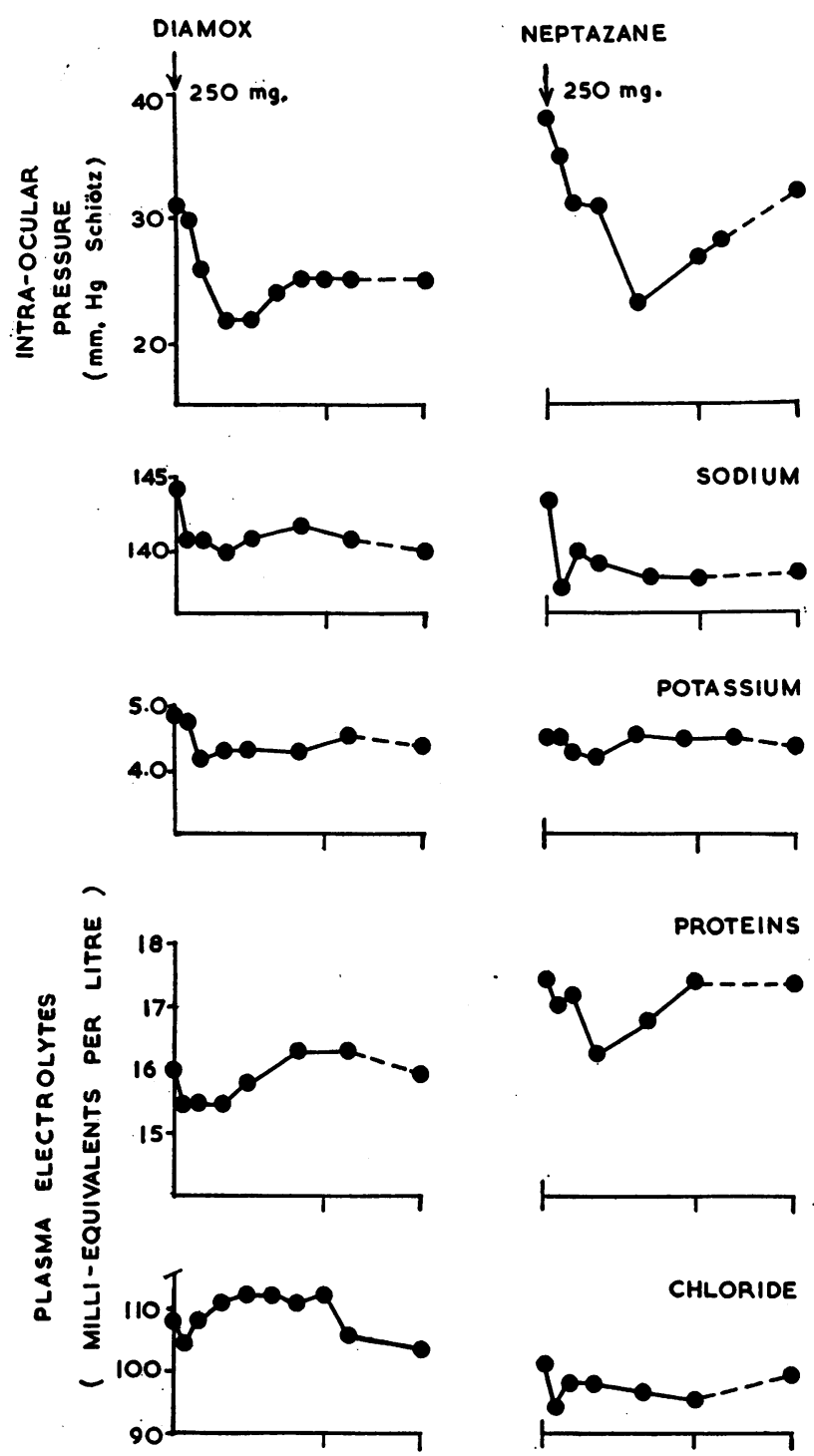

PROTEINS
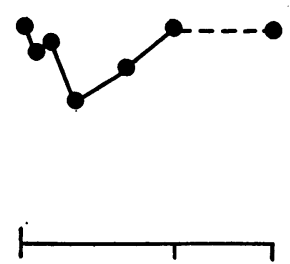

CHLORIDE

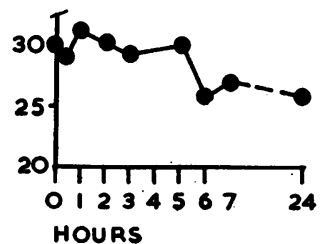

BICARBONATE
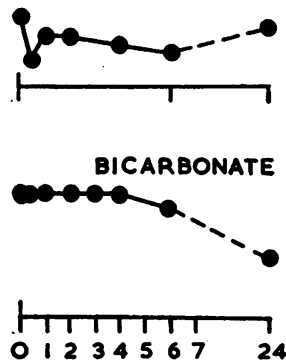

0123456724

Fig. 4.-Comparison of the effect of Neptazane and of Diamox on plasma electrolytes in relation to intra-ocular pressure. 
(iii) The differences in the urinary output (average for three cases in each instance) were much more striking than the changes in the blood (Fig. 5).
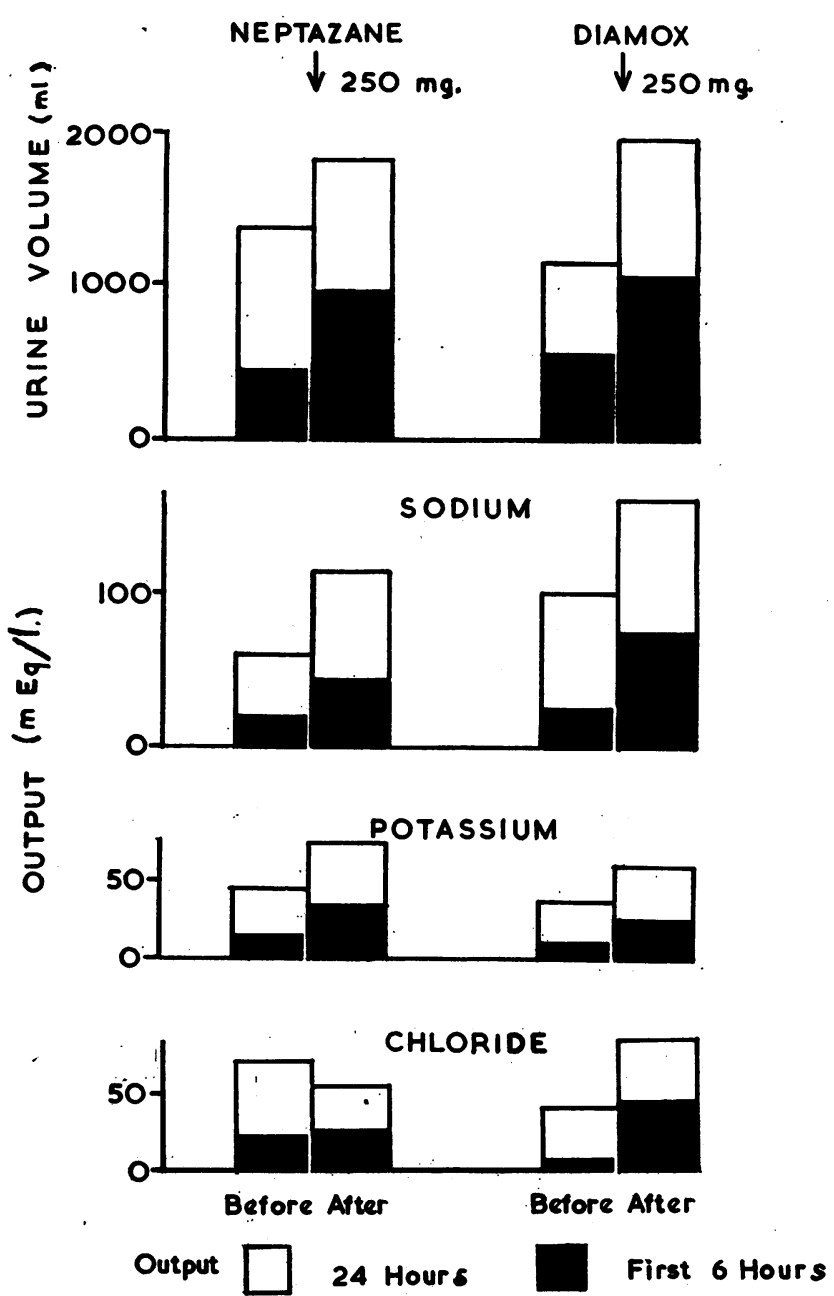

Fig. 5.-Average output of urine before and after Neptazane or Diamox.

In the 24-hr output the diuresis caused by Neptazane was much less (an increase of 33 per cent. as compared with 75 per cent. after Diamox). The output of sodium and potassium was much larger (an increase of 90 and 80 per cent. as compared with 60 and 58 per cent. respectively).

The output of chloride actually declined by 17 per cent. whereas it increased by 110 per cent. after Diamox.

Although the bicarbonate output was not measured quantitatively it was decidedly less after Neptazane than after Diamox. 


\section{Effects of Repeated Doses of Neptazane}

In order to discover the optimum size and frequency of the dose applicable for continuous therapy, Neptazane was given over a period of several days in three individual subjects, as follows (Fig. 6):

(i) In an initial dose of $250 \mathrm{mg}$. followed at intervals of $48 \mathrm{hrs}$ by doses of $125 \mathrm{mg}$. (Case 1).

(ii) In doses of $125 \mathrm{mg}$. in two subjects at intervals of $24 \mathrm{hrs}$ (Case 4) and $12 \mathrm{hrs}$ (Case 5) respectively.

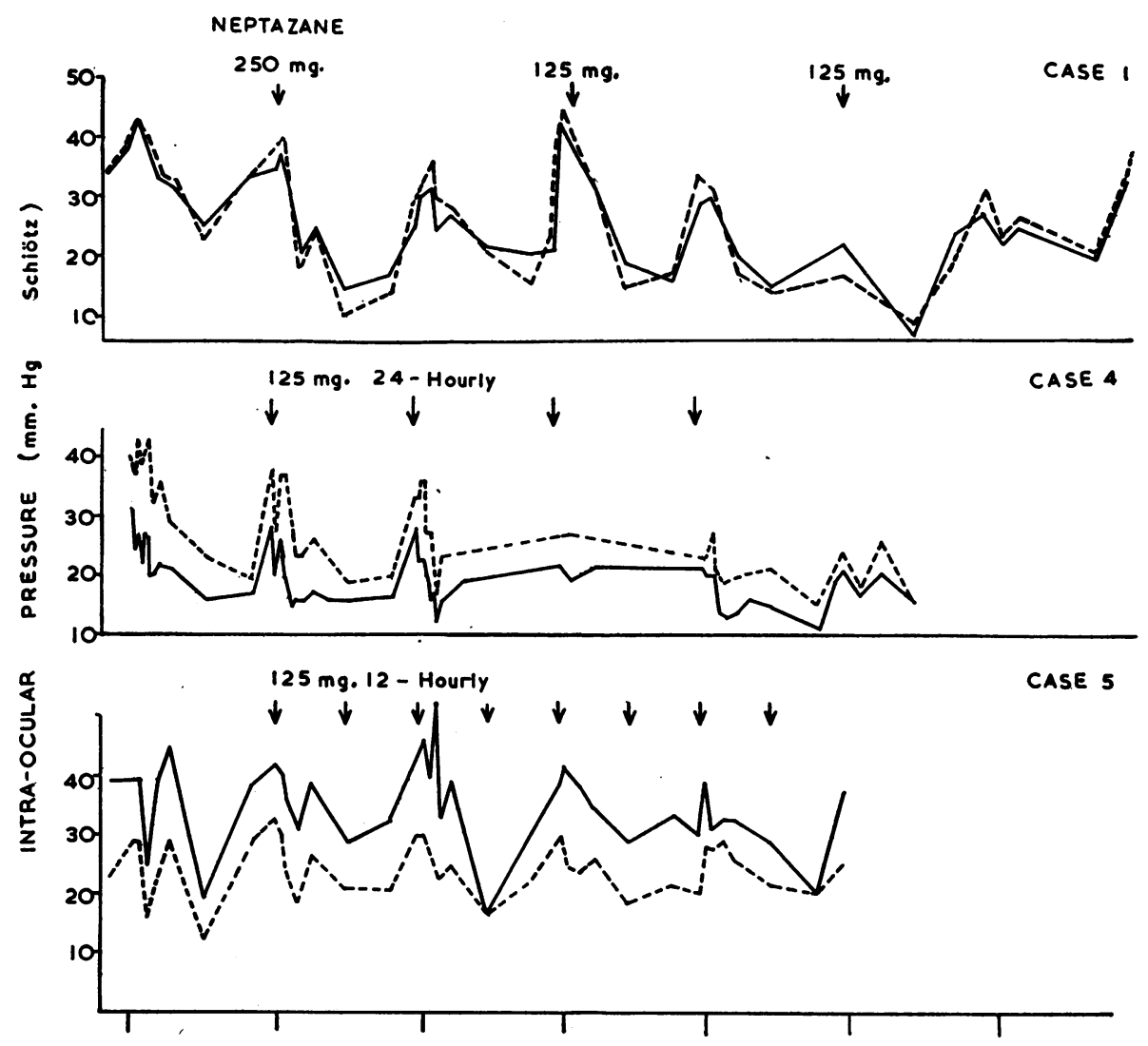

FIG. 6.-Effect of repeated doses of Neptazane on intra-ocular pressure.

(a) Ocular Response.-The intra-ocular pressure was adequately controlled by doses given at intervals of 48 and $24 \mathrm{hrs}$. It showed an immediate response to each dose and an overall gradual decline with a lessening of the peaks so long as the administration of the drug continued, but began to rise again $24 \mathrm{hrs}$ after the last dose. 
There appeared to be no advantage in giving the drug 12-hrly as opposed to 24-hrly ( $c f$. Cases 4 and 5), in fact the overall effect was not so satisfactory. The optimum dose appeared to be $125 \mathrm{mg}$. administered at intervals of $24 \mathrm{hrs}$.

(b) Systemic Response.-Blood analyses were restricted to the more significant constituents-sodium, potassium, chloride, and proteins. During each period of fall in intra-ocular pressure there was a corresponding fall in sodium, chloride, and proteins (Fig. 7).

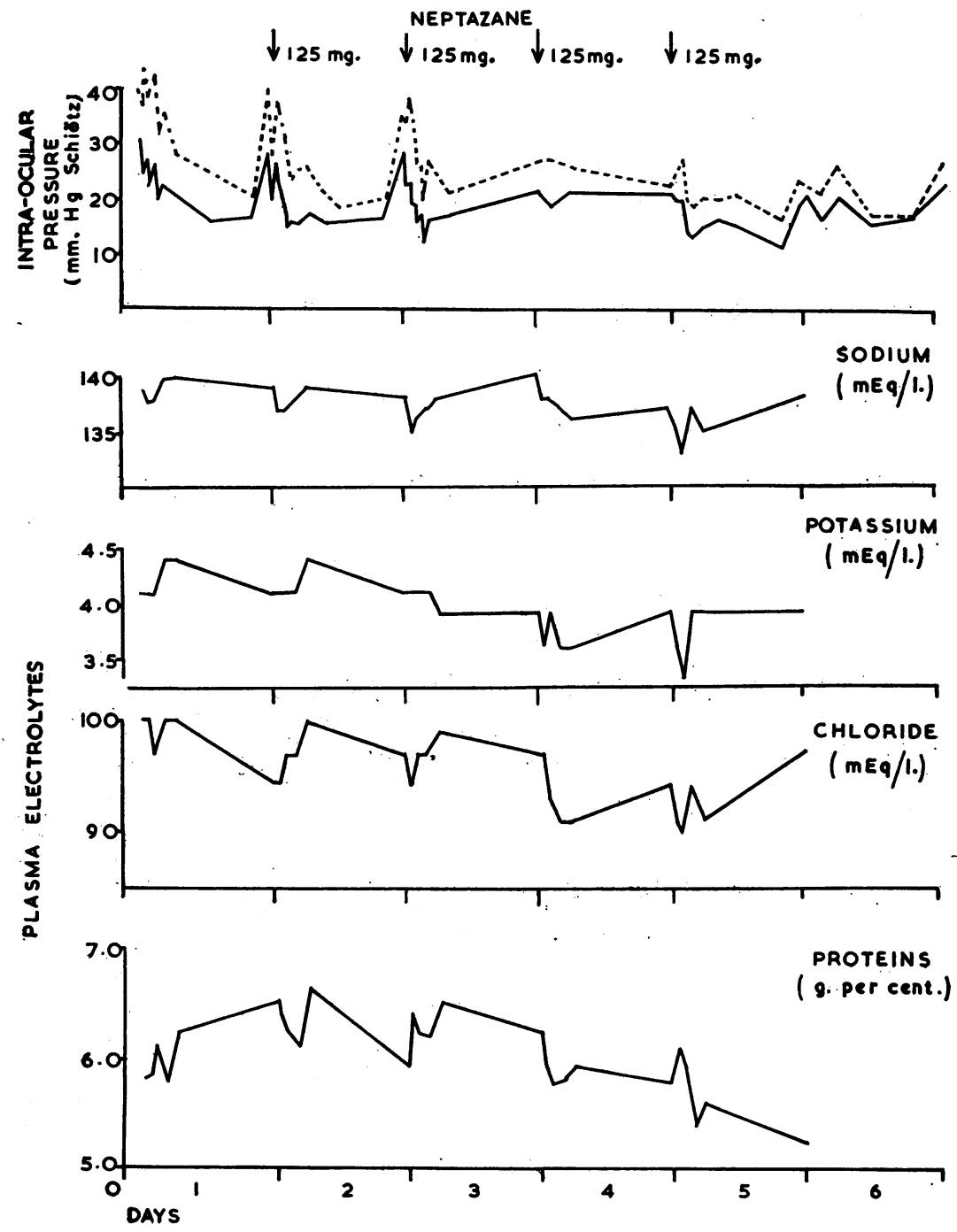

Fig. 7.-Changes in intra-ocular pressure and plasma electrolytes after repeated doses of Neptazane. 
There was an overall decrease in the level of chloride, proteins, and potassium during the 4 days of the test. The daily fluctuations in sodium became larger, but the level was well maintained (Fig. 7).

On each of the first 2 days the urinary changes were substantially the same as after a single dose, but thereafter the response declined and the urinary volume and output of sodium and potassium reverted to a predosage level. Chloride excretion declined steadily from the first day, and the urine remained alkaline for a shorter time after each dose (Fig. 8).
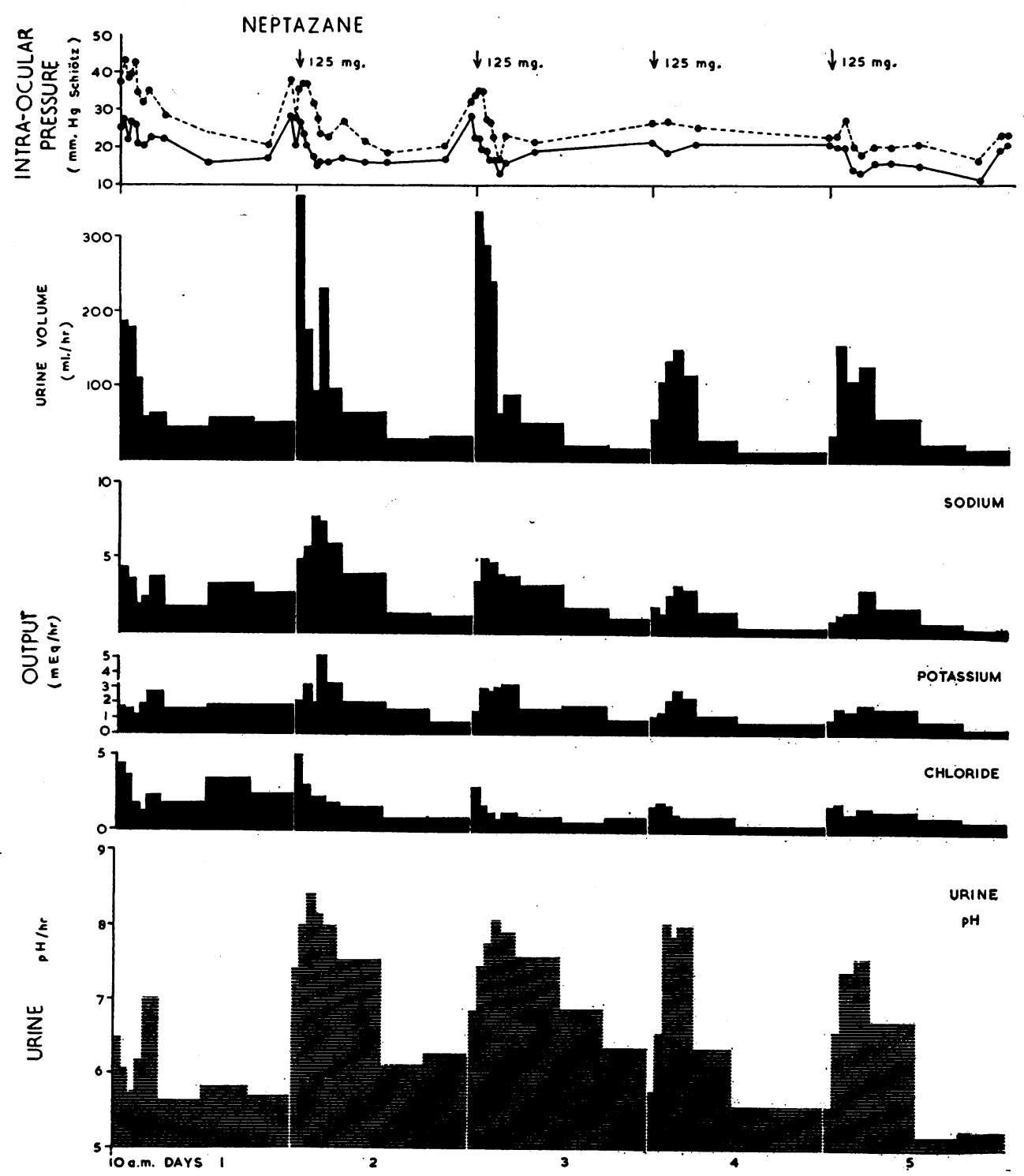

FIG. 8.-Intra-ocular pressure and urinary output after daily doses of Neptazane. 
Neptazane given 12-hrly augmented the total daily output of electrolytes, especially of potassium. This was regarded as an undesirable feature, since it gave no greater control of the intra-ocular pressure.

(c) Comparison of Effect of Repeated Doses of Neptazane or Diamox.-In this instance the effects of a daily dose of $125 \mathrm{mg}$. Neptazane were compared with those of a daily dose of $250 \mathrm{mg}$. Diamox over a period of 3 to 4 successive days.

(i) The most striking difference was that, whereas Neptazane could be relied upon to maintain a continuous control of intra-ocular pressure and in some instances to produce an increasing effect on each successive day, in the majority of cases Diamox had a diminishing effect (Fig. 9), unless (as was found by previous experience) potassium bicarbonate was given as an adjuvant (Campbell, Jones, Renner, and Tonks, 1957).

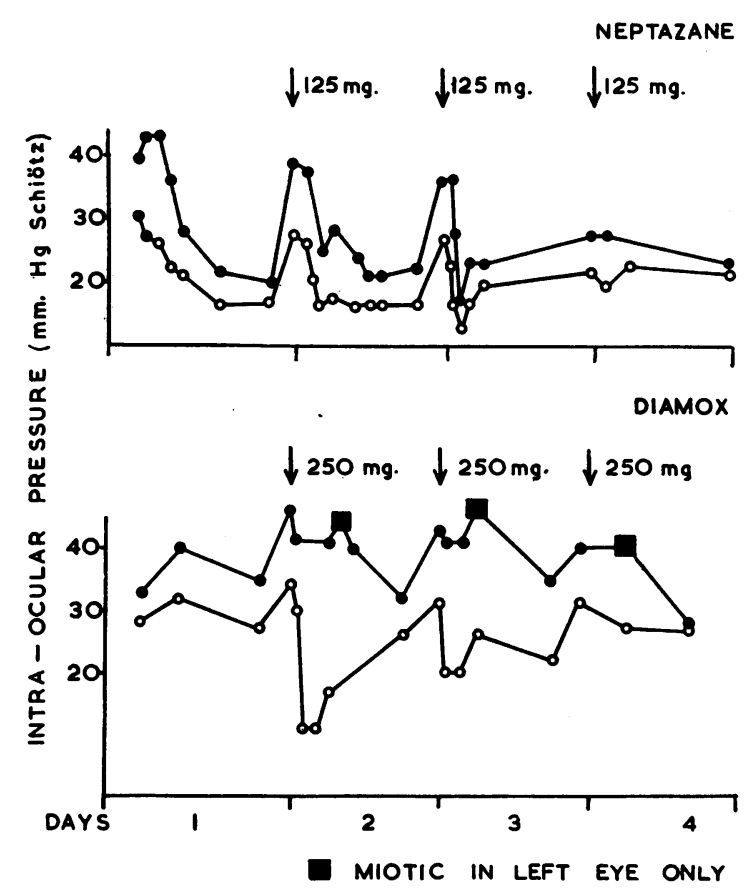

FIG. 9.-Comparison of the effect of repeated doses of Neptazane and of Diamox on intra-ocular pressure.

(ii) The electrolytes in the blood varied in much the same way with the difference that no hyperchloraemia, such as occurs after Diamox, was observed. 
(iii) Diuresis tended to decrease after the first day, as did the output of sodium and potassium after either Neptazane or Diamox. The output of chloride declined markedly after continuous administration of Neptazane (Fig. 10).

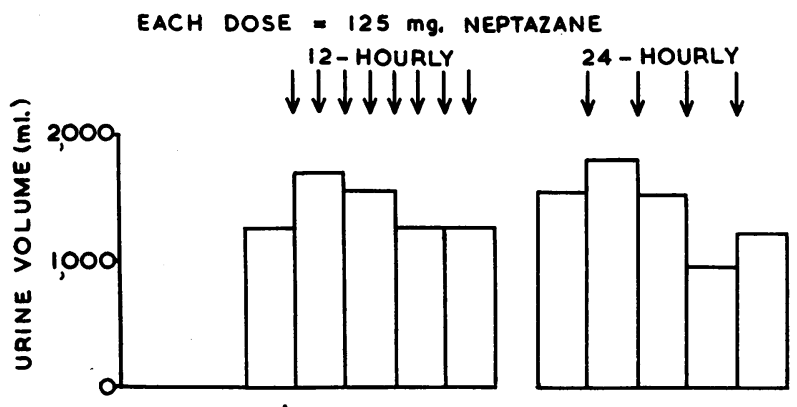

SODIUM
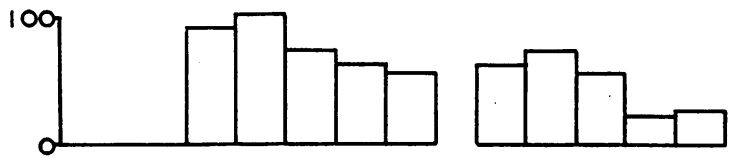

$\overline{\dot{D}}$
w
E
5
5
0
5
0

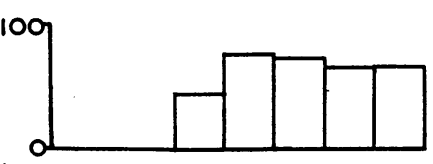

POTASSIUM
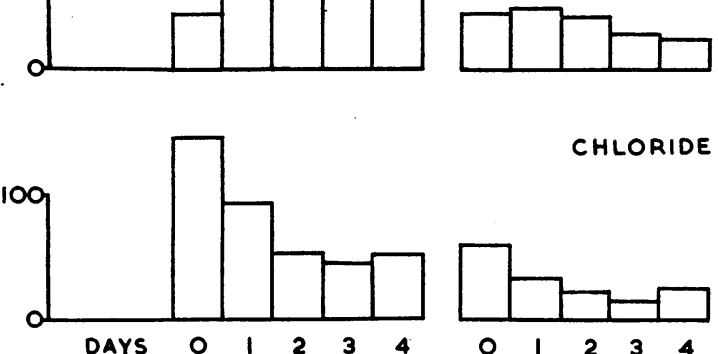

DAY $O=$ CONTROL DAY.

Eoch daily output is the total for 24 hours

FIG. 10.-Comparison of the effect of 12-hrly and 24-hrly Neptazane on output of urine. Day $0=$ Control day. Each daily output is the total for 24 hirs.

\section{Summary}

\section{(1) Effect of Single Dose}

(a) The effect of a single dose of $250 \mathrm{mg}$. Neptazane on intra-ocular pressure is materially the same as that of $250 \mathrm{mg}$. Diamox, but the action is slower and more prolonged. 
(b) During the period of fall in intra-ocular pressure there is an accompanying fall in sodium, potassium, chloride and proteins of the blood, whereas the fall in bicarbonate does not occur for 6 to $7 \mathrm{hrs}$.

(c) A moderate diuresis occurs during the same period, and is accompanied by a marked rise in the excretion of sodium and potassium, and a decline in the excretion of chloride.

\section{(2) Effect of Repeated Doses}

(a) The optimum effect on reduction of intra-ocular pressure was obtained by the administration of $125 \mathrm{mg}$. Neptazane at intervals of $24 \mathrm{hrs}$. There was an immediate response to each successive dose and an overall decline in intra-ocular pressure which was maintained so long as the drug was continued.

(b) Each dose gave rise to an immediate fall in sodium, potassium, chloride, and proteins in the blood, and to an overall decline in all but sodium, the level of which was well maintained.

(c) On each of the first 2 days the urinary changes were the same as after a single dose. Thereafter the response declined and the urinary volume and output of sodium and potassium reverted to a predesage level. Chloride excretion declined from the first day.

(d) Increased frequency of dosage, e.g. $125 \mathrm{mg}$. administered 12-hrly, gave no better control of intra-ocular pressure and it augmented the output of potassium.

\section{(3) Therapeutic Indications for the Use of Neptazane}

There is a close similarity in the action of Neptazane and Diamox on the intra-ocular pressure and in their systemic effects.

The evidence presented in this paper confirms the clinical findings of Becker (1957), and it is hoped that it will provide reliable criteria for the therapeutic use of Neptazane.

(i) Owing to its slowness of action, Neptazane is less suitable than Diamox for the rapid reduction of intra-ocular pressure in cases of acute glaucoma.

(ii) A dose of $250 \mathrm{mg}$. Neptazane is equivalent to $250 \mathrm{mg}$. Diamox where more prolonged action is desired, or in cases which do not respond to Diamox.

(iii) Neptazane is particularly suitable for long-term therapy as, in contrast to Diamox, it continues to be effective, whereas the effect of Diamox declines unless it is potentiated by miotics or by the simultaneous administration of potassium bicarbonate. A dose of $125 \mathrm{mg}$. Neptazane, administered daily, appears to be adequate, but this might be increased to $250 \mathrm{mg}$. given at intervals of 24 or $48 \mathrm{hrs}$. 
(iv) The administration of the drug more than once in $24 \mathrm{hrs}$ is undesirable, since it increases the bodily loss of potassium, and gives no greater reduction of intra-ocular pressure.

In conclusion, the most noticeable physiological feature of the action of Neptazane is the close correlation between the fall in the intra-ocular pressure with the fall in the electrolytes and their increased excretion. The osmotic changes which it causes in the plasma may in fact be greater than those which follow the use of Diamox, since the induced diuresis is comparatively less and the excretion of sodium and potassium is higher.

It would be interesting to investigate more precisely how closely the intra-ocular pressure in man responds to osmotic changes in the blood, when the latter occur naturally or are induced therapeutically.

Some very stimulating work on this particular relationship as it occurs in rabbits has recently been published by Cole (1959).

My thanks are due to Dr. A. C. Hempel and to Miss E. Tonks for their clinical and biochemical investigations; to Messrs Lederle for a supply of Neptazane; to the Medical Illustration Department of the Institute of Ophthalmology; and to Miss W. Robbins for her clerical assistance.

\section{REFERENCES}

BECKER, B. (1956). Amer. J. Ophthal., 41, 522.

(1957). A.M.A. Arch. Ophthal., 58 N.S., 862. and CoNSTANT, M. A. (1955). Ibid., 54 N.S., 321

CAmpbell, D. A., Jones, M., RenNer, N. E. A., and Tonks, E. (1957). Brit.J. Ophthal., 41, 746. , RENNER, N. E. A., and TONKS, E. (1958). Ibid., 42, 732. ,TONKS, E., and JONES, M. (1956). Ibid., 40, 283.

COLE, D. F. (1959). Ibid., 43, 268.

LANGHAM, M. E. (1958). Ibid., 42, 577.

and LEE, P. M. (1957). Ibid., 41, 65.

MAREN, T. H. (1956). J. Pharmacol., 117, 385.

Sisson, G. M. and Maren, T. H. (1956). Fed. Proc., 15, 484. 